\title{
EXPLORING THE POWER OF SPORTING CELEBRITY ENDORSEMENTS: A COMPARISON OF CONTRASTING SPORTS
}

Fiona Davies, Cardiff Business School, U.K.

Stephanie Slater, Cardiff Business School, U.K.

\begin{abstract}
In sports marketing fans are regarded as critical influencers of product success. Celebrity sponsorships are used to strengthen fan patronage since they enhance the level of engagement that fans have with the product, building image and reputation. Schaefer and Keillor (1997), Bush, Martin and Bush (2004), Braunstein and Zhang (2005) and Tingchi Lui, Yu-Ying \& Minghua (2007) confirm the advertising benefit that companies gain through the use of celebrity figures in marketing campaigns. Through celebrity marketing the brand acquires a positive and elevated meaning of the product portfolio line being endorsed (Madrigal, 2001). Brand community membership is developed in response to the social identity that individuals place on being affiliated to sporting events and the sense of community that is developed by fans when attending sport events such as Wimbledon in tennis.
\end{abstract}

This paper investigates sporting celebrity brand images and the effect of celebrity endorsement on brand choice. The perceived images of two contrasting sports stars within each of two sports (tennis and Formula One motor racing) are evaluated, and the effects of their potential endorsement explored for a range of products, in order to evaluate and compare the extent to which the benefits of celebrity endorsement can be stretched.

The research methodology involved collection of both primary and secondary data. The web archives of one UK broadsheet newspaper (The Guardian) and one UK tabloid newspaper (The Daily Mirror) were searched for articles, blogs and associated comments relating to the four spoitsmen, either from the start of their professional career or as far back as available. The websites and archives of the celebrity magazines "Now" and "Heat" were also searched for any references to the sportsmen, and the sportsmen's own web pages were perused. These enabled the researchers to build a picture of each sportsman's brand image and how celebrity endorsement power might have changed over time. This information was used to develop the measurement instrument.

The questionnaire design was modelled around conceptual structures that support a variety of academic theoretical arguments. Primary research was carried out using an internet questionnaire developed using the software package Qualtrics. The design of the questions had two objectives; to explore respondents' perceptions of the sportsmen, and to investigate the effect of links between sports, stars and brands. The questionnaire was administered through Facebook links and e-mails to friends, family and colleagues. Respondents were requested to complete the survey and then pass the link on to others. The survey was available for a total of 12 days. The final sample consisted of 102 respondents, 54 males and 48 females. $52 \%$ stated they were interested in tennis, $42 \%$ in motor racing, and $79 \%$ in sport in general.

The findings suggest that there is a high level of association between celebrity profile, product, and brand choice. Endorsement of a product relevant to the sportsperson's own sport was effective, while endorsement of a product relating to the contrasting sport was not. However differences were observed in the endorsement evaluation effect between the two sports disciplines; F1 drivers were perceived more strongly than tennis players as celebrities, and appeared to have greater value as endorsers of a product unrelated to sport. Findings further confirm the positive associations generated in the mind of consumers when marketing companies use role models as tools for enhancing a consumer's expectation of a product or service. This can lead to brand and product spillovers, given that consumers' purchase of a non-sports related product such as a mobile phone appears to be influenced by sport celebrity endorsement. Consequently, purchasing intent is not restricted to the purchase of sports products, but is rather determined by the cool image that the celebrity endorsement gives to the product.

References available upon request 